\section{1}
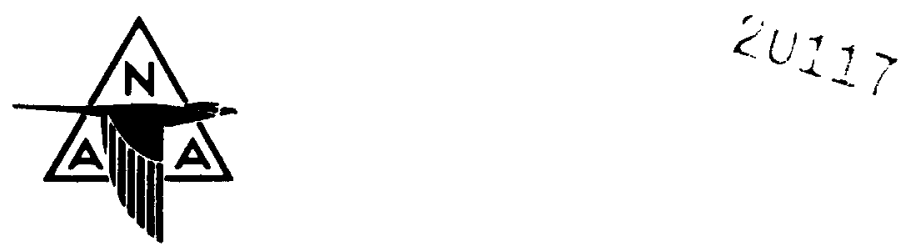

\title{
GAS COOLING OF A POROUS HEAT SOURCE
}

WRITTEN BY:

L. GREEN, Jr.

This document is

PUBLICLY RELEASABLE

(uesh Kinus)

Autherizing Ofictia

Date:

$2-1-2012<$
WORK DONE BY:

L. GREEN, Jr.

B. J. LEMKE

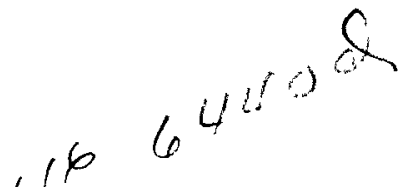

C. R. MALMSTROM, GROUP LEADER, ENGINEERING LABORATORY

S. SIEGEL-ASSOCIATE DIRECTOR

C. STARR - DIRECTOR

\section{ATOMIC ENERGY RESEARCH DEPARTMENT \\ NORTHAMERICAN AVIATION, INC.}

P. O. BOX 309 


\section{DISCLAIMER}

This report was prepared as an account of work sponsored by an agency of the United States Government. Neither the United States Government nor any agency Thereof, nor any of their employees, makes any warranty, express or implied, or assumes any legal liability or responsibility for the accuracy, completeness, or usefulness of any information, apparatus, product, or process disclosed, or represents that its use would not infringe privately owned rights. Reference herein to any specific commercial product, process, or service by trade name, trademark, manufacturer, or otherwise does not necessarily constitute or imply its endorsement, recommendation, or favoring by the United States Government or any agency thereof. The views and opinions of authors expressed herein do not necessarily state or reflect those of the United States Government or any agency thereof. 


\section{DISCLAIMER}

Portions of this document may be illegible in electronic image products. Images are produced from the best available original document. 
This report is distributed according to the category "Physics" as given in the "Distribution Lists for United States Atomic Energy NonClassified Research and Development Reports" TID-4500, July 19, 1951. 


\section{ACKNOWLEDGMENT}

The author wishes to acknowledge helpful discussions with Professor Pol Duwez of the California Institute of Technology, at whose suggestion the foregoing analysis was made. 
A limiting case of solid-fluid heat transfer is examined, in which a gas passes through a porous wall of high specific surface with heat generation within the solid material. Dimensionless temperature profiles in the wall are presented in terms of the rate of heat generation, rate of flow, and thermal properties of the gas and solid. The pressure drop across the wall is approximated by using an average wall temperature and assuming isothermal conditions. Temperature profiles, pressure drops, and pumping-power/power-output ratios are calculated for the hypothetical case of a heated graphite wall cooled by helium. It is found that the thermal dependence of the gas viscosity may produce a minimum in the pressure-drop versus flow-rate curve, and it appears that favorable pumping-power-output ratios can be obtained by the use of high pressures. The problem of temperature stability in a gas-cooled porous solid is pointed out and the need for experimental work emphasized. Use of the sweat-cooling technique for high-pressure, high-temperature ducts is suggested. 15 nefereen

This report is based on studies conducted for the Atomic Energy Commission under Contract AT-11-1-GEN-8. 


\section{INTRODUCTION}

The possibility of using porous construction to achieve efficient heat removal from a power-producing solid, although not a new idea, has recently been emphasized by Tsien. ' Such construction would reconcile high power density with small temperature differences in the solid and the coolant fluid. The purpose of the present paper is to study a limiting case of heat removal from a porous wall by a gaseous coolant when the surface per unit volume of the porous structure is high enough that the temperature of the fluid at any point in its path may be considered to be substantially the same as that of the adjacent solid. Studies of sweat-cooled porous metals ${ }^{2}$ indicate that this assumption is not unreasonable.

\section{TEMPERATURE DISTRIBUTION}

The assumptions involved in the temperature distribition problem are summarized below:

1. In the porous wall, gas temperatire and solid temperature are approximately equal.

2. The gas flow and heat flow are steady and one-dimensional. Convective effects neglected by this assumption will alter the temperature distribution in the approaching gas at low flow rates but should not greatly influence the conditions prevailing within the wall.

3. All heat conduction in the wall takes place in the solid.

4. The thermal conductivities of the solid and gas and the specific heat of the gas are constant.

The one-dimensional flow of a gas at weight flow rate $G$ through a porous wall of thickness $l$ is depicted in Fig. 1. If the rate of heat generation per unit volume in the wall is $q$, a heat balance on an element of volume in the wall (see Fig. 2) leads to the equation 


$$
\text { Wall: } \quad \frac{d^{2} T}{d x^{2}}-\frac{G c p}{k_{s}} \frac{d T}{d x}+\frac{q}{k_{s}}=0
$$

A similar balance on a volume element in the approaching gas gives

$$
\text { Gas: } \frac{d^{2} T}{d x^{2}}-\frac{G c p}{k g} \frac{d T}{d x}=0
$$

Subject to the conditions that

$$
\begin{array}{rlrl}
\text { at } x & =-\infty, & \mathrm{T} & =\mathrm{T}_{0} \\
\mathbf{x} & =0 & \mathrm{~T} & =\mathrm{T}_{1} \\
\mathrm{x} & =l & \left.\mathrm{k}_{\mathrm{g}} \frac{\mathrm{dT}}{\mathrm{dx}}\right|_{\text {gas }} & =\left.\mathrm{k}_{\mathrm{s}} \frac{\mathrm{dT}}{\mathrm{d} \mathbf{x}}\right|_{\text {wall }} \\
\mathrm{T} & =\mathrm{T}_{0}+\frac{\mathrm{q} l}{\mathrm{Gc}}=\mathrm{T}_{2}
\end{array}
$$

solutions of Eqs. (1) and (2) are

$$
\begin{aligned}
& \text { Wall: }(0 \leqslant x \leqslant l) \quad \frac{T-T_{0}}{\frac{q l}{G c_{p}}}=\frac{x}{\ell}+\frac{1-e^{-\frac{G c_{p} \ell}{k_{s}}\left(1-\frac{x}{\ell}\right)}}{\frac{G c_{p} \ell}{k_{s}}} \\
& \text { Gas: } \\
& (-\infty \leqslant x \leqslant 0) \\
& \frac{T-T_{0}}{\frac{g l}{G c_{p}}}=\frac{1-e^{-\frac{G c_{p} l}{k_{s}}}}{\frac{G c_{p} l}{k_{s}}} e^{\frac{G c}{k} c^{\ell}\left(\frac{x}{\ell}\right)}
\end{aligned}
$$


Fig. 3 presents curves of the dimensionless temperature distribution in the wall as given by Eq. (7) for different values of the parameter ( $G c_{p} l / k_{s}$ ). As expected, it is seen that uniformity of the wall temperature (desirable from the thermal stress viewpoint) is promoted by a high thermal conductivity in the solid. Manipulation of Eq. (7) gives a relative temperature uniformity index independent of the rate of power production in the form of the ratio

$$
\frac{T_{1}-T_{0}}{T_{2}-T_{0}}=\frac{1-e^{\frac{-G c_{p} \ell}{k_{s}}}}{\frac{G c_{p} \ell}{k_{s}}}
$$

which approaches unity with decreasing flow rate as shown in Fig. 4. The absolute temperature difference across the wall, however, increases with decreasing flow rate, reaching a maximum value of

$$
\lim _{G \rightarrow 0}\left(T_{2}-T_{1}\right)=\frac{q l^{2}}{2 k_{s}}
$$

For calculation of the pressure drop across the wall (as discussed below) it is convenient to use an average wall temperature

$$
\mathrm{T}_{\text {avg }}=\frac{1}{\ell} \int_{0}^{l} \mathrm{Td} \mathbf{x}
$$

which with use of Eq. (7) may be expressed in the form

$$
\frac{T_{a v g}-T_{0}}{\frac{q l}{G c_{p}}}=\frac{1}{2}+\frac{\frac{G c_{p} \ell}{k_{s}}-1+e^{-\frac{G c_{p} \ell}{k_{s}}}}{\left(\frac{G c_{p} l}{k_{s}}\right)^{2}}
$$


This average temperature index is presented as a function of $\left(\mathrm{G}_{\mathrm{p}} \ell / \mathrm{k}_{\mathrm{s}}\right)$ in Fig. 5. Since the index varies only between 0.5 and 1.0 , the average wall temperature is roughly inversely proportional to the flow rate, as would be expected.

\section{FLOW RESISTANCE}

Experiments with porous metals ${ }^{3}$ have shown that the pressure gradient in a perfect gas in steady, isothermal flow through a moderately fine-grained porous medium can be expressed by a quadratic equation of the type

$$
-\frac{d\left(p^{2}\right)}{d x}=\alpha(2 b T \mu) G+\beta\left(\frac{2 b T}{q}\right) G^{2}
$$

where $b=R / M$ is the specific gas constant, $\mu$ is the dynamic viscosity, and the coefficients $\alpha$ and $\beta$ are length parameters characteristic of the structure of the porous material itself and are called the viscous and inertial resistance coefficients of the material. The viscous coefficient $\alpha$, with dimensions $\left[L^{-2}\right]$, characterizes the flow resistance of the material in the regime of "creeping" flow where inertia forces are negligible. The inertial coefficient $\beta$, of dimension $\left[L^{-1}\right]$, provides a measure of the additional resistance due to microscopic accelerations of the fluid within the interstices of the material.

A commonly encountered correlation of pressure-drop versus flow rate data for porous media is formulated in terms of a Reynolds number and friction factor based upon the so-called "equivalent capillary diameter" calculated by invoking an analogy between the laws of Darcy and Poiseuille, which are valid only for low velocity flows. This analogy would explain the deviation from Darcy's law at higher flow rates by the onset of turbulence within the pores which are visualized as straight, parallel capillaries. The porous-metal flow studies, ${ }^{3}$ however, showed that a single length parameter is not sufficient to correlate pressure-drop versus flow-rate curves over a large range of flow rates, which in general are not "parallel" and may even cross one another in some cases of sufficiently different porous structures. 
The necessity of having two independent length parameters for characterization of a porous medium of arbitrary complexity considerably reduces the advantage of the dimensionless friction-factor versus Reynold's-number presentation. Although a Reynold's-number and friction-factor for a porous structure of a geometry defying description may be defined by writing Eq. (13) in dimensionless groups, ${ }^{3}$ no convenience in calculations is achieved by so doing. With the introduction of heat generation within the solid material, as in the present problem, the complications involved in dimensionless representation are so great that its use is not justified, and greater simplicity is achieved by direct calculation of the pressure drops from Eq. (13) in the form above.

An exact solution of the pressure-drop problem would require integration of Eq. (13) across the thickness of the heated wall, substituting at each point the proper temperature from Eq. (7) and the corresponding value of the dynamic viscosity of the coolant gas. (This procedure, of course, assumes that the coefficients $\alpha$ and $\beta$ are independent of temperature.) ${ }^{*}$ For thin walls of high conductivity, however, a simpler calculation using the average wall temperature from Eq. (12) is sufficiently accurate.

\section{HELIUM FLOW THROUGH A GRAPHITE WALL}

As a specific example of gas cooling of a heat-producing porous solid, calculations of the anticipated performance of a porous graphite heater for helium gas have been made. Graphite as a heater material for use with inert gases is of interest because it has been found to exhibit remarkable mechanical properties at temperatures of incandescence. ${ }^{4,5,6}$ The hypothetical heater wall thickness is taken as 0.5 inch and the material is assumed to be National Carbon Company Grade 30 commercial porous graphite, pertinent properties of which are presented in Table I. The high-temperature viscosity of helium, yielded by an intrepid extrapolation of the data of Akin and Norris ${ }^{7}$ is shown in Fig. 6.

Calculated temperature profiles in the above wall and in the approaching gas are shown in Fig. 7 for a rate of heat generation of $10 \mathrm{Btu} / \mathrm{in}^{3}$-sec and for

* Flow experiments with porous metals at temperatures up to $1200^{\circ} \mathrm{F}$ support this assumption. 
several different weight flow rates. Fig. 8 presents curves of the gradient of the square of the pressure across the wall versus flow rate (assuming an inlet temperature of $500^{\circ} \mathrm{R}$ ) for heat generation rates of $0,0.1,1.0$, and $10 \mathrm{Btu} / \mathrm{in}^{3}$-sec. The curves are terminated at the point where the wall temperature reaches the sublimation temperature of graphite (roughly $6600^{\circ} \mathrm{F}$ at atmospheric pressure). The most striking feature of these curves is that the flow rate appear to be a double-valued function of the flow resistance, due to the increase of the gas viscosity with temperature, and operation of the heater at the minimum point for greatest efficiency is indicated. The most extreme case $\left(q=10 \mathrm{Btu} / \mathrm{in}^{3}\right.$-sec) is investigated further in Fig. 9, which gives the pressure drop across the wall for inlet pressures of 5, 10, and 20 atmospheres, thus emphasizing the advantage of operating the heater at high pressure. Because of the relative weakness of the porous structure (see Table I) a small pressure difference across the wall is imperative.

A figure of merit commonly applied to heat exchangers is the ratio of the power required for the pumping of the fluid to the power removed as thermal energy. Since the pumping power used in forcing a perfect gas through the wall is

$$
\mathrm{W}=-\mathrm{G} \int \frac{\mathrm{dp}}{\rho}=\mathrm{bT}_{\text {avg }} \mathrm{G} \ln \frac{\mathrm{p}_{1}}{\mathrm{p}_{2}}
$$

and the heat removal rate is

$$
Q=G c_{p}\left(T_{2}-T_{0}\right)
$$

the figure of merit becomes

$$
\frac{W}{Q}=\frac{{ }^{b} T_{\text {avg }}}{c_{p}\left(T_{2}-T_{0}\right)} \ln \frac{p_{1}}{p_{2}}
$$

or for small pressure drops relative to the average absolute pressure 


$$
\frac{W}{Q}=\frac{b T_{a v g}}{c_{p}\left(T_{2}-T_{0}\right)} \frac{\left(p_{1}-p_{2}\right)}{p_{a v g}}
$$

This ratio is plotted in Fig. 10 as a function of flow rate for the same case as in Fig. 9. It appears that in a high-pressure system the $W / Q$ ratio may be $r e-$ duced to a value low enough to permit useful power production from the heated gas. Gilliland ${ }^{8}$ has shown analytically that the $W / Q$ ratio for a gaseous heattransfer system varies inversely as the square of the system pressure, and this prediction is obeyed by the data of Fig. 10 as is shown in Fig. 11, which indicates that a pressure of 40 atmospheres would be required to reduce the $\mathrm{W} / \mathrm{Q}$ ratio for the present case to 0.1 per cent.

It must be emphasized that the above results do not show conclusively that low $\mathrm{W} / \mathrm{Q}$ ratios with gaseous coolants can be achieved with certainty by merely using porous construction. In preliminary experiments by the author using a nitrogen-cooled, electrically-heated, porous-wall $\mathrm{Ni}-\mathrm{Fe}$ tubular heat exchanger with a power density of $0.088 \mathrm{Btu} / \mathrm{in}^{3}-\mathrm{sec}, \mathrm{W} / \mathrm{Q}$ ratios from 0.2 to 2.0 (depending upon the flow rate) were obtained. Since the mean pressure in the system (which exhausted to the atmosphere) averaged about 2 atmospheres, it may be presumed that a system pressure of about 20 atmospheres could effect a $W / Q$ ratio of the order of 1 per cent. It may certainly be concluded that the idea appears attractive enough to justify an experimental investigation of its possibilities.

\section{TEMPERATURE STABILITY}

The curves of Figs. 8, 9, 10, and 11 immediately suggest operation of the porous heater at the point of minimum pressure drop. If for some reason non-optimum operation is desired, a choice of two alternative positions (hightemperature, low-flow or low-temperature, high-flow) is available for each value of the pressure difference established across the wall. The order of commencing the coolant circulation and the power generation then determines which position is attained.

*Unpublished work conducted at the Jet-Propulsion Laboratory of the California Institute of Technology, 1948. 
Instability of the wall temperature, however, may arise from the temperature dependence of the gas viscosity. Should a hot-spot in the wall exist due to some inhomogeneity of the porous material, for instance, the increased viscosity would tend to cut down the flow at the point, thus increasing the local temperature and aggravating the situation. The wall temperature could conceivably increase in this fashion until failure occurred. In the abovementioned experiments by the author, however, no such instability was noted. In this case, however, the power density was low, operation was well into the high-flow, low-temperature region, and a considerable amount of heat was conducted out through the electrodes. Because of the difficulty in analyzing the temperature stability problem in the porous heat source, it appears that an experimental approach would be more fruitful. It may be presumed, however, that stability will be promoted by high thermal conductivity in the porous solid, high heat capacity in the gas, and high flow rate, Stability considerations may indeed require operation on the high-flow side of the optimum point, where the flow resistance is dominated by the quadratic, non-viscous term of Eq. (13). Experimental work will be required to resolve this problem, however.

\section{CONCLUSION}

The foregoing discussion has explored the problem of heat removal from a porous heat source by a gaseous coolant. Consideration of the specific case of a helium-cooled graphite wall showed that efficient operation from the point of view of pumping power would require the use of a system under a pressure of at lcasi several atmospheres. The use of such high pressures at the extreme temperature desired poses a serious problem of ducting or containment of the system, since the creep of most materials at such temperatures prohibits their use. In this connection the "sweat cooling" technique proposed by Duwez" for use in the cooling of rocket motors appears to offer interesting possibilities. A section of a high-pressure, high-temperature, sweat-cooled duct is idealized in Fig. 12. Analysis 10,11 and experiment ${ }^{12,13}$ have shown that effective cooling of the wall can be achieved by a relatively small flow of coolant, as is indicated in Fig. 13. Since the effectiveness of the porous-wall cooling method (in cases with a temperature gradient along the wall) has been found to be greatest for wall materials of low thermal conductivity, ${ }^{10}$ the use of ungraphitized carbon is indicated for 
the present proposed application. For a stream temperature of $4000^{\circ} \mathrm{F}$ for instance, a coolant flow (from a reservoir at $100^{\circ} \mathrm{F}$ ) of rate only 0.2 per cent of the main stream rate would reduce the inner wall surface temperature to about $2450^{\circ} \mathrm{F}$. The presence of the porous shield would probably eliminate the need for high-temperature materials in the outer casing. In this scheme the hot inner duct would be subject to only a small compressive stress required by the pressure difference driving the coolant, thus minimizing the creep problem, and the high pressure would be contained by the cool outer casing. Sweat-cooled ducts as applied to a gas turbine (the coolant air being taken from the compressor) have been considered by Moore and Grootenhuis, ${ }^{14}$ who report that the power loss may approach 1 per cent at low coolant flows. It is possible that the sweatcooling technique may make feasible the operation of a gaseous system at temperatures and pressures high enough to exploit the high permissible power density peculiar to a porous heat source. 


\section{NOMENC LA TURE}

b Gas constant $=\mathrm{R} / \mathrm{M}$ (in. $\left./{ }^{\circ} \mathrm{R}\right)$

$c_{p} \quad$ Specific heat of gas (Btu/1b- ${ }^{\circ} \mathrm{F}$ )

g Gravitational acceleration (in. $/ \mathrm{sec}^{2}$ )

G Weight flow rate of gas (lb/in. ${ }^{2}-\mathrm{sec}$ )

$\mathrm{k}$ Thermal conductivity of gas (Btu/in. $-\sec -{ }^{\circ} \mathrm{F}$ )

$k_{s} \quad$ Apparent (bulk) thermal conductivity of solid (Btu/in. - sec- ${ }^{\circ} \mathrm{F}$ )

$\ell$ Thickness of wall (in.)

L Dimension of length

M Molecular weight of gas (lb/lb-mol)

$\mathrm{p} \quad$ Fluid pressure $\left(\mathrm{lb} / \mathrm{in}^{2}\right)$

q Rate of heat generation in wall (Btu/in. ${ }^{3}-\mathrm{sec}$ )

Q Rate of heat removal from wall (Btu/in ${ }^{2}-\mathrm{sec}$ )

$R \quad$ Universal gas constant $\left(10.73 \frac{\mathrm{lb}}{\mathrm{in.}{ }^{2}} \cdot \frac{\mathrm{ft}^{3}}{\mathrm{lb}-\mathrm{mol}} \cdot \frac{1}{{ }_{\mathrm{o}}}\right)$

$\mathrm{T}$ Temperature $\left({ }^{\mathrm{O}} \mathrm{F}\right.$ or $\left.{ }^{\mathrm{O}} \mathrm{R}\right)$

W Power required for pumping of fluid (Btu/in. ${ }^{2}$-sec)

x Length variable

a Viscous resistance coefficient of porous material (in. ${ }^{-2}$ )

$\beta \quad$ Inertial resistance coefficient of porous material (in. ${ }^{-1}$ )

$\mu \quad$ Dynamic viscosity of gas (lb sec/in. ${ }^{2}$ )

$\rho \quad$ Specific weight of gas $\left(\mathrm{lb} / \mathrm{ft}^{3}\right)$ 
TABLE I

Some Properties of Grade 30 Porous Graphite ${ }^{a}$

\begin{tabular}{|c|c|c|}
\hline Thermal Conductivity ${ }^{b}$ & $9.3 \times 10^{-4}$ & $\mathrm{Btu} / \mathrm{in} .{ }^{\mathrm{o}} \mathrm{F}-\mathrm{sec}$ \\
\hline Tensile Strength ${ }^{\mathrm{D}}$ & 80 & $\mathrm{lb} / \mathrm{in}^{\mathrm{C}}$ \\
\hline Compressive Strength ${ }^{b}$ & 520 & $\mathrm{lb} /$ in. $^{2}$ \\
\hline Viscous Resistance Coefficient ${ }^{c}$ & $8.4 \times 10^{6}$ & in. $^{-2}$ \\
\hline Inertial Resistance Coefficient ${ }^{c}$ & $4.9 \times 10^{3}$ & in. -1 \\
\hline
\end{tabular}

a National Carbon Company

b From National-Acheson handbook

c Calculated from water-flow data obtained by M. R. Hatfield 15 


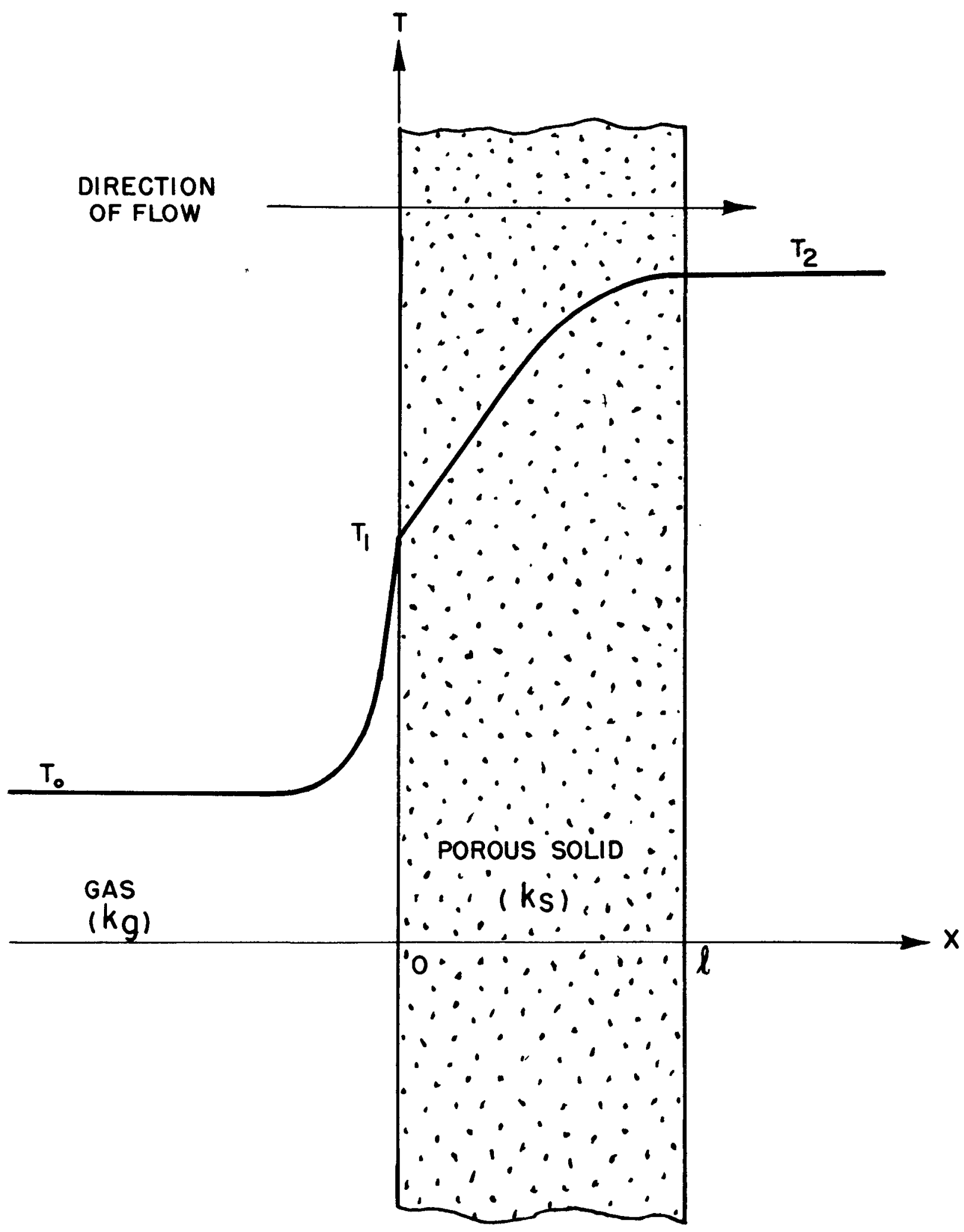

Figure 1. Temperature Distribution in a Gas in One-Dimensional Flow Through a Porous Wall Generating Heat. 


$$
\begin{aligned}
& G c_{p} T-k_{s} \frac{d T}{d x} \rightarrow \overbrace{\sqrt{d x} q d x} \rightarrow G c_{p}\left(T+\frac{d T}{d x} d x\right)-k_{s}\left(\frac{d T}{d x}+\frac{d^{2} T}{d x^{2}} d x\right) \\
& \text { ELEMENT OF UNIT AREA }
\end{aligned}
$$

Figure 2. Heat Balance on a Volume Element in Wall. 


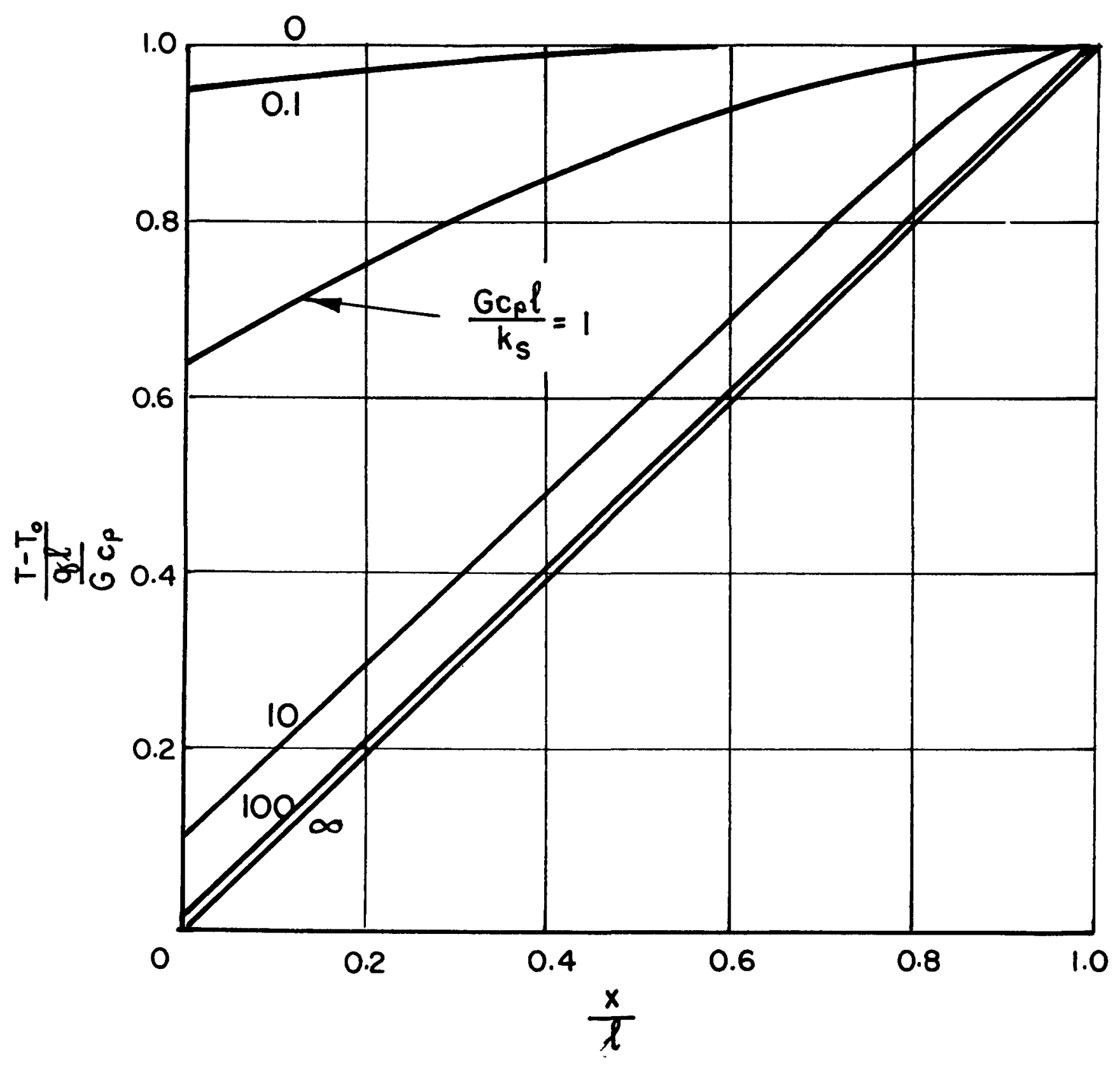

Figure 3. Dimensionless Temperature Distribution in Porous Wall for Different Values of the Parameter $\mathrm{Gc}_{\mathrm{p}} / \mathrm{R}_{\mathrm{s}}$. 


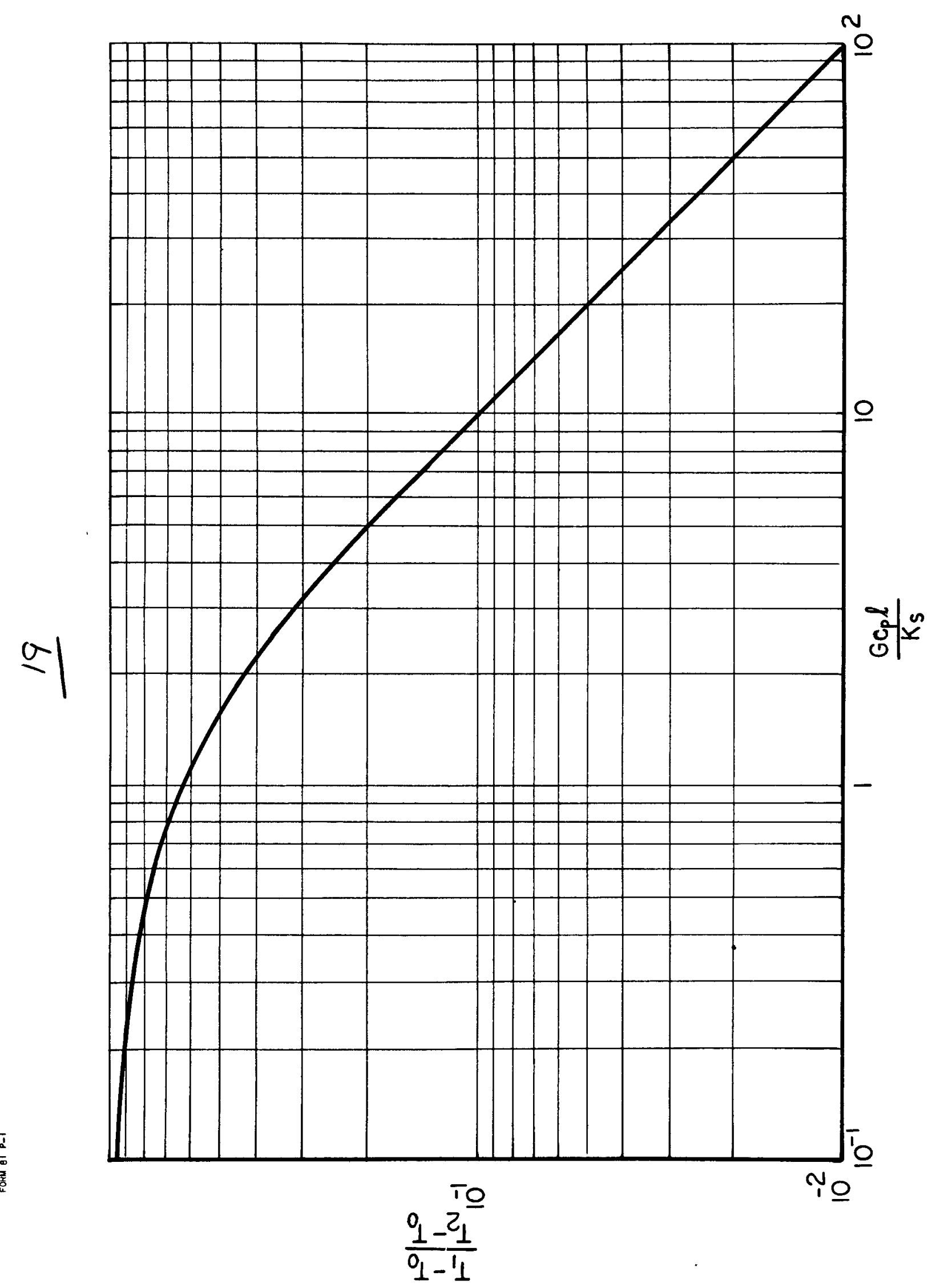

 


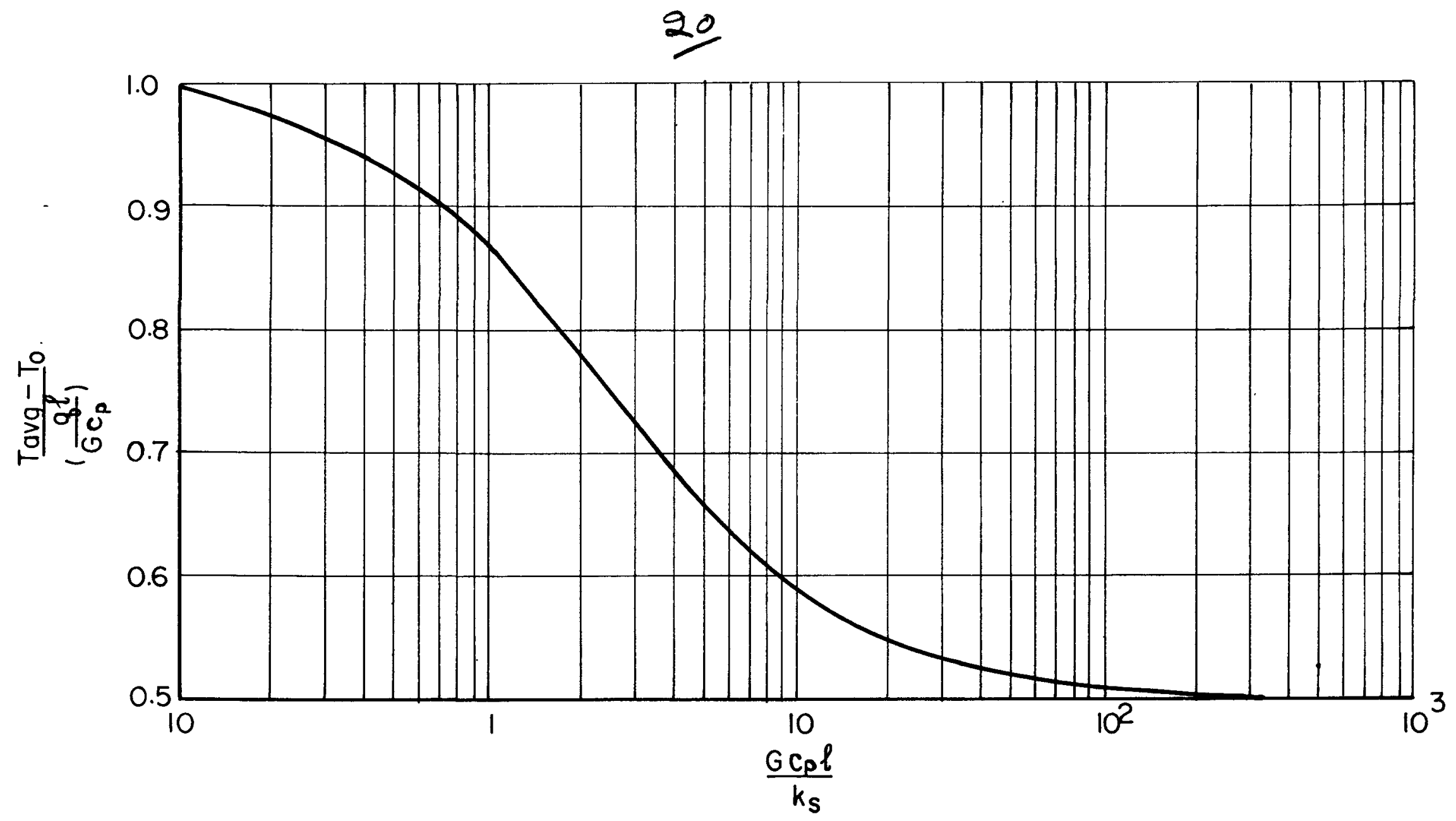

Figure 5. Average Temperature Index vs. $G c_{p} / R_{s}$. 


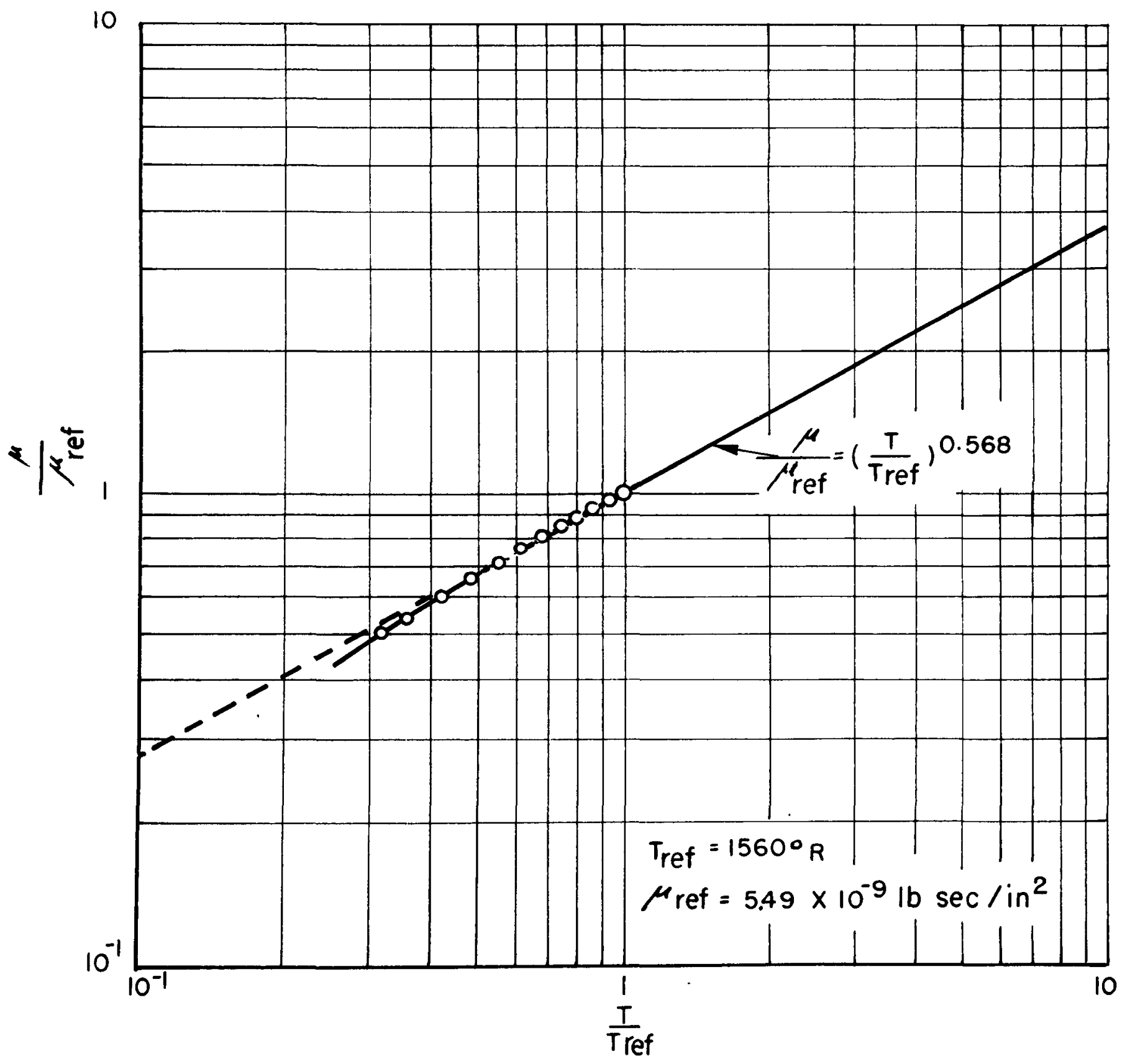

Figure 6. Thermal Dependence of the Dynamic Viscosity of Helium Extrapolated from the Date of Akin and Norris (Ref. 7). 


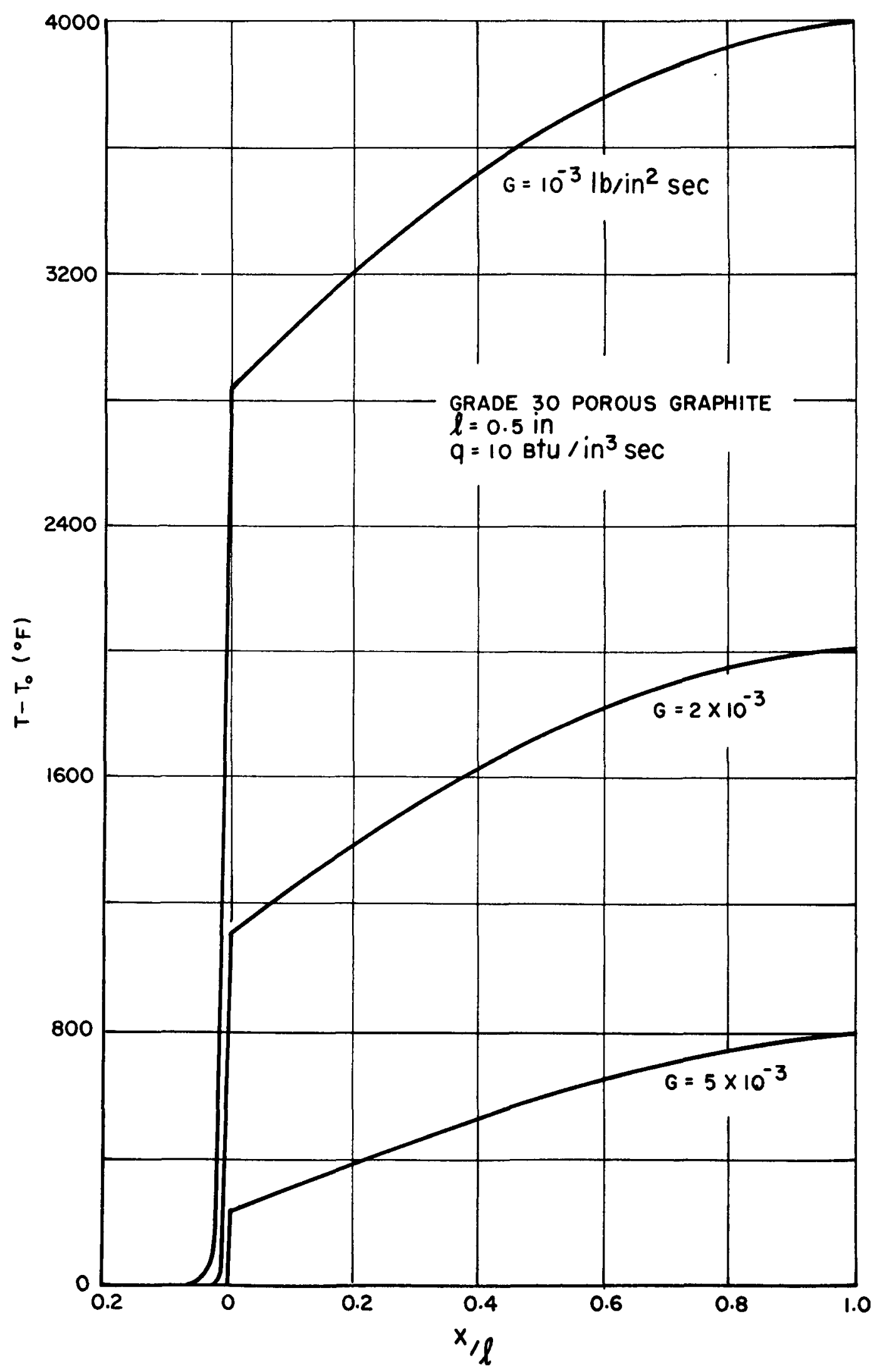

Figure 7. Typical Temperature Profiles in Gas and Porous Wall for a High Rate of Heat Generation. 


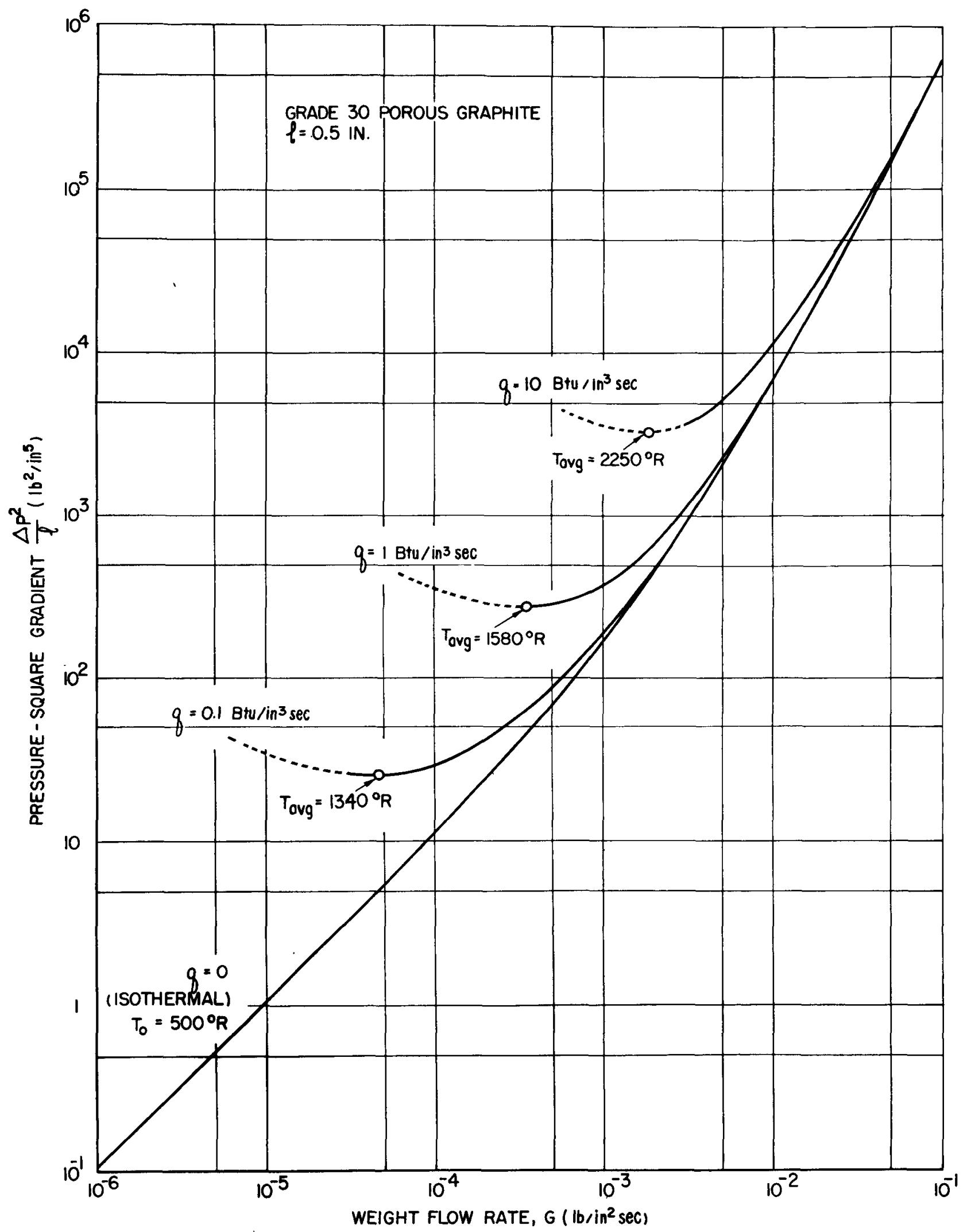

Figure 8. Pressure-Square Gradient Across Porous Wall vs. Weight Flow Rate for Different Rates of Heat Generation (Dashed Portion Indicates Region Where Viscosity of Gas Was Calculated by Extrapolation). 


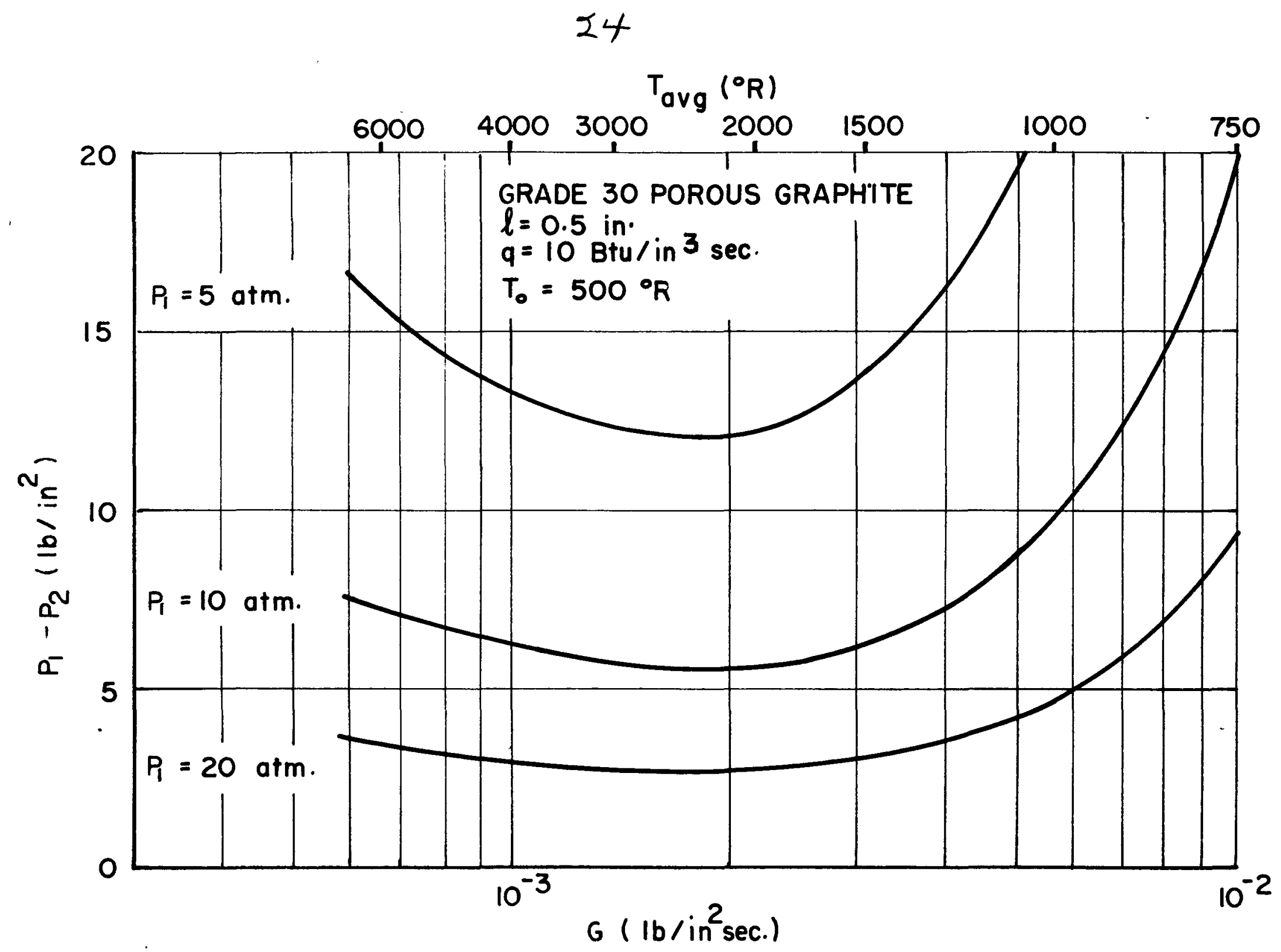

Figure 9. Pressure Drop Across Wall vs. Flow Rate for Different Inlet Pressures. 


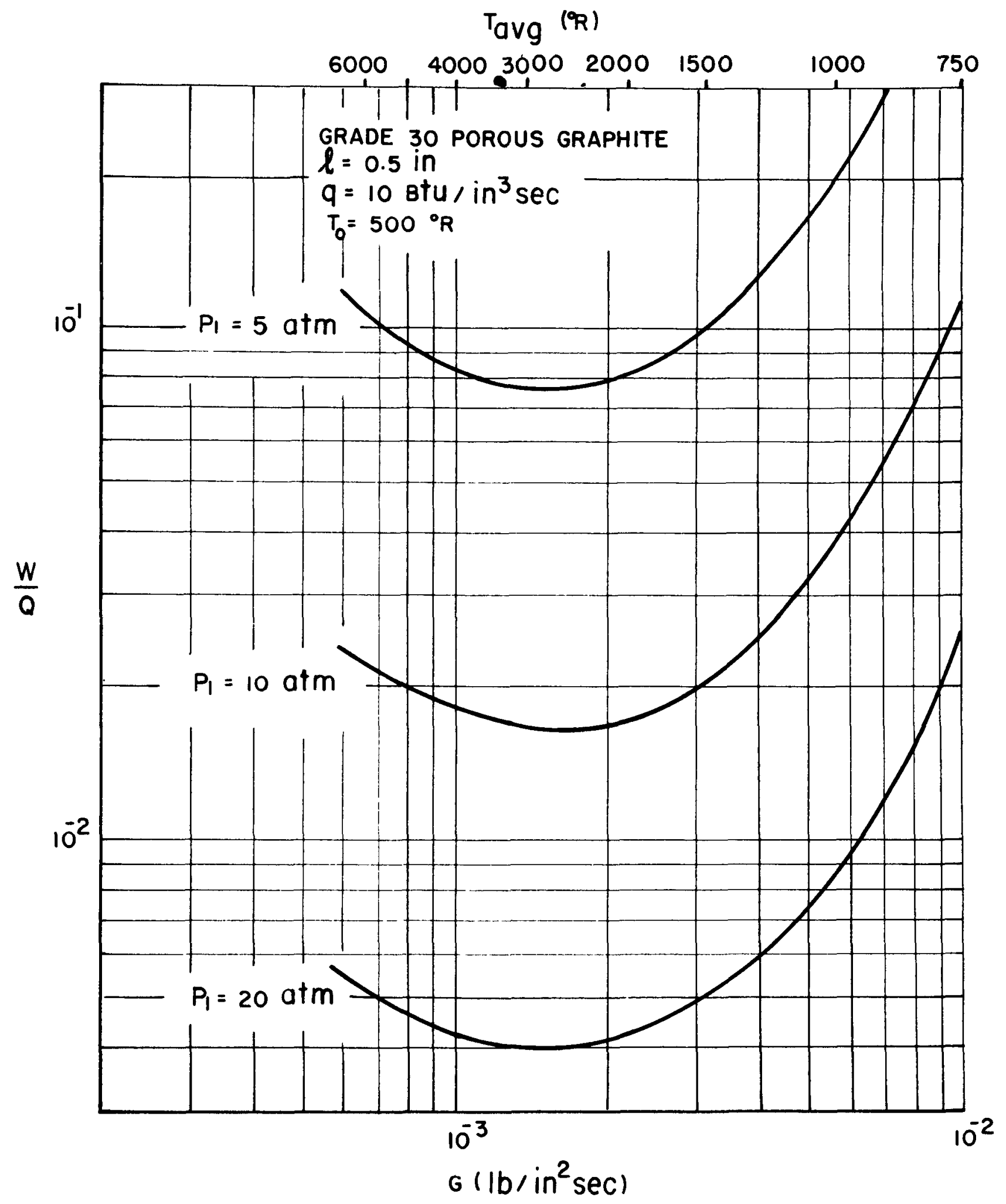

Figure 10. Pumping-Power/Power-Output Ratios vs. Flow Rate for Different Inlet Pressures. 


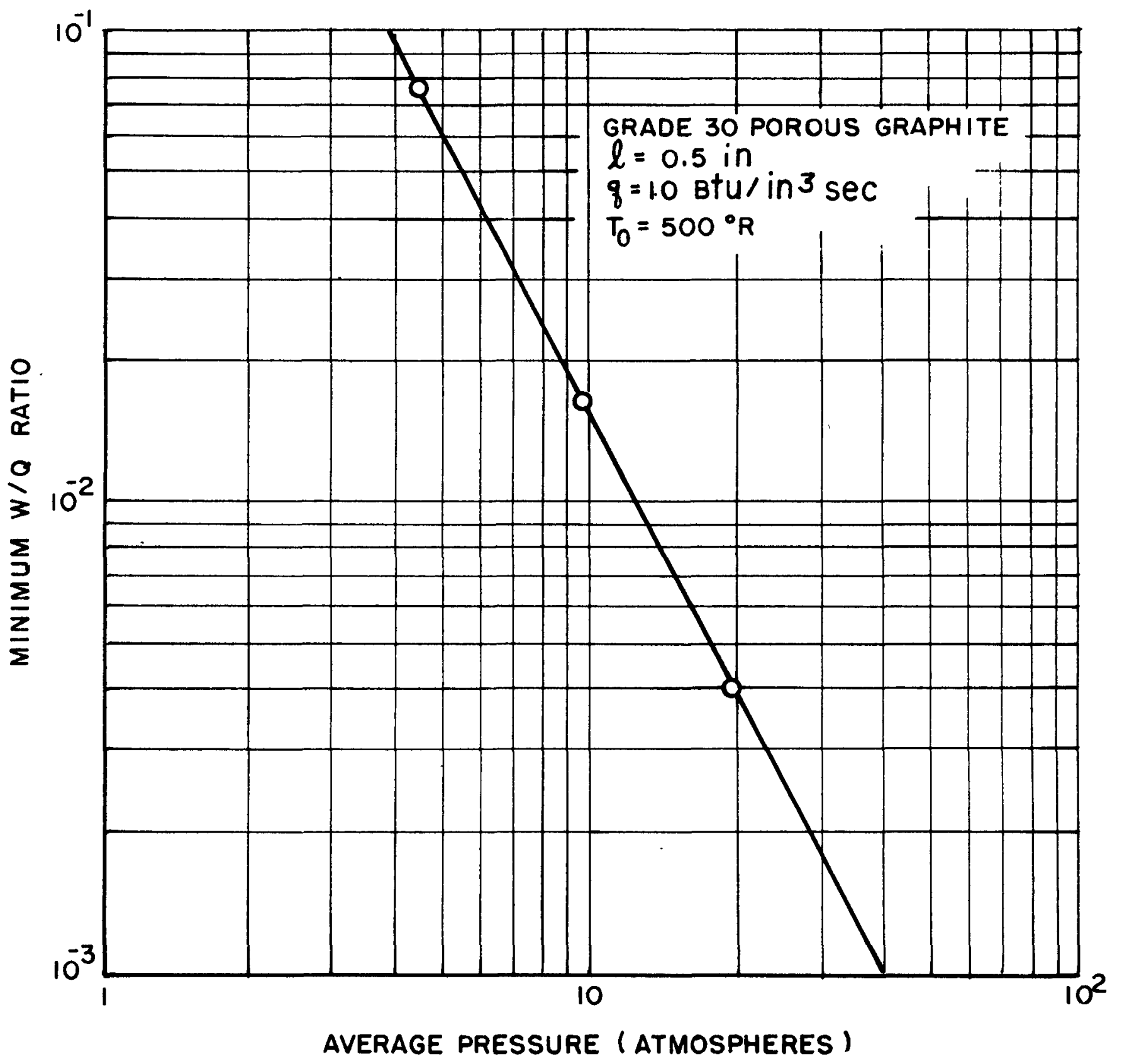

Figure 11. Minimum W/Q Ratio vs. Average Pressure. 


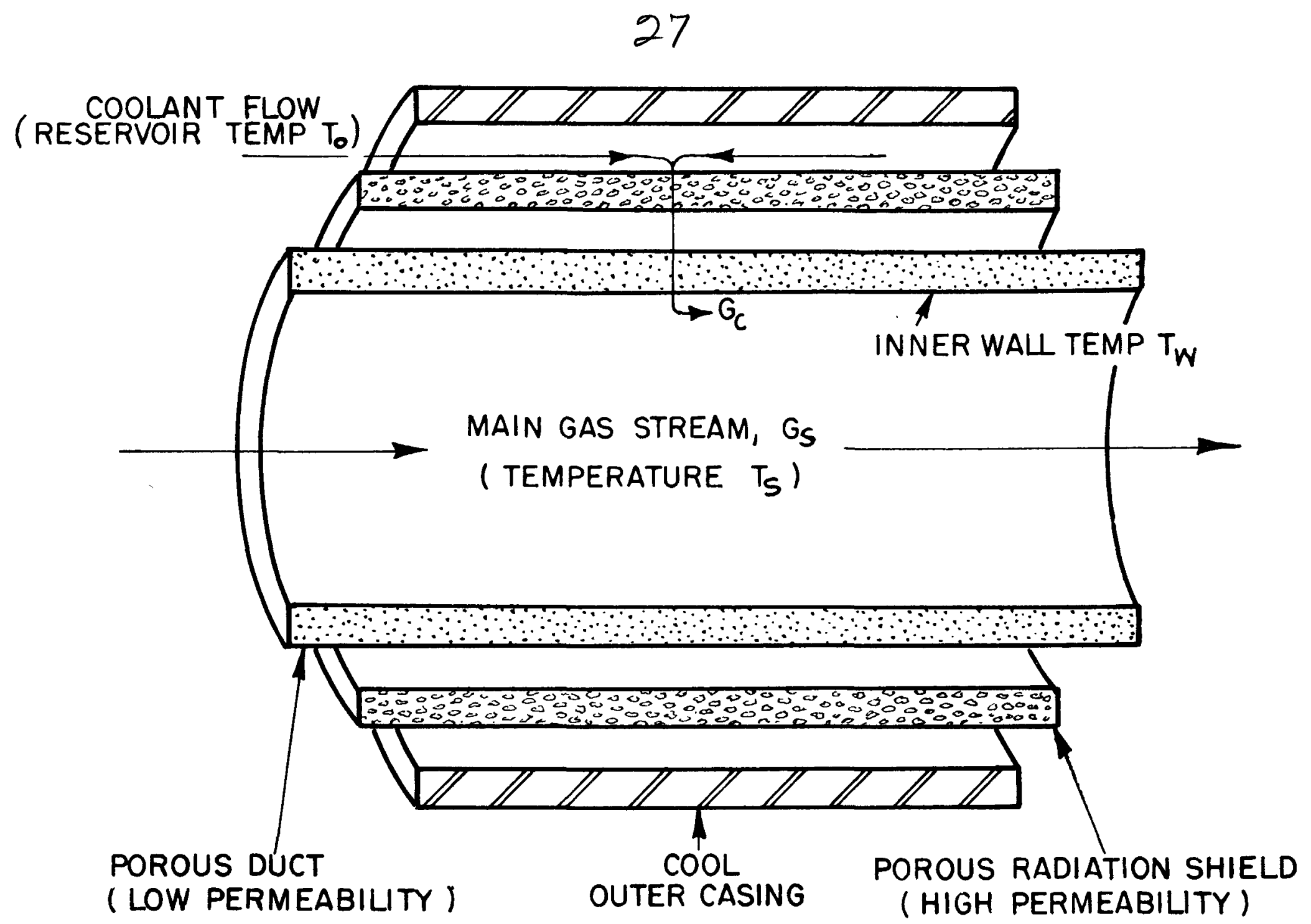

Figure 12. Schematic Section of High-Pressure Sweat-Cooled Duct. 


\section{8}

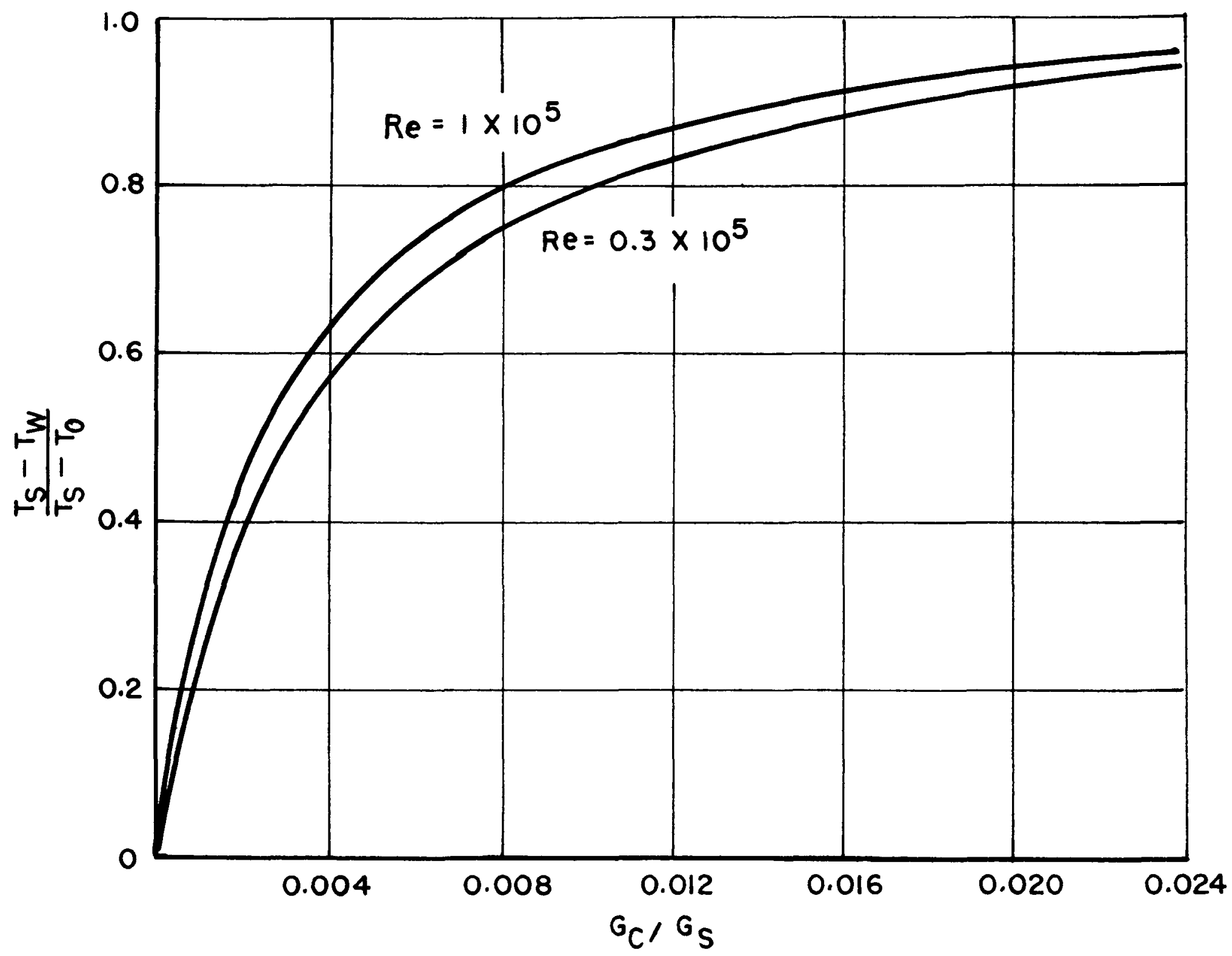

Figure 13. Effect of Sweat Cooling on Wall Temperature for Two Different Main-Stream Reynolds Numbers (from Ref. 11). 


\section{REFERENCES}

1. Tsien, H. S., The Science and Engineering of Nuclear Power, vol. II, Clark Goodman, ed., Addison-Wesley Press, Inc. (1949). p. 194.

2. Weinbaum, S., and H. L. Wheeler, Jr., "Heat Transfer in Sweat-Cooled Porous Metals," Jour. App. Phys., 20, 113 (1949).

3. Green, L., Jr., and P. Duwez, "Fluid Flow Through Porous Metals," Jour. App. Phys., 18, 39 (1951).

4. Malmstrom, C. R., R. D. Keen and L. Green, Jr., "Some Mechanical Properties of Graphite at Elevated Temperatures, "Jour. App. Phys., 22. 593 (1951).

5. Faris, F. E., L. Green, Jr. and C. A. Smith, "The Thermal Dependence of the Elastic Moduli of Polycrystalline Graphite," to be communicated to the Jour. App. Phys.

6. Green, L., Jr., "The Behavior of Graphite under Alternating Stress, " to be published in Jour. App. Phys.

7. Akin, S. W. , and R. H. Norris, "Thermodynamic Properties of Helium at High Pressures and Temperatures, "G. E. General Engineering and Consulting Laboratory, April 23, 1947.

8. Gilliland, E. R., The Science and Engineering of Nuclear Power, vol. I, Clark Goodman, ed., Addison-Wesley Press, Inc. (1947). p. 342.

9. Duwez, P., "Experimental Study of Cooling by Infiltration of a Fluid Through a Porous Material, "Sixth International Congress for Applied Mechanics, Paris (1946).

10. Rannie, W. D., "A Simplified Theory of Porous Wall Cooling, " Progress Report 4-50, November 24, 1947, Jet Propulsion Laboratory, Calif ornia Institute of Technology.

11. Grootenhuis, P., and N. P. W. Moore, "Some Observations on the Mechanism of Sweat Cooling, " Seventh International Congress for Applied Mechanics, London, $\underline{3}, 106$ (1948).

12. Duwez, P., and H. L. Wheeler, Jr., "Experimental Study of Cooling by In jection of a Fluid Through a Porous Material, "Jour. Aero. Sci. , 15, 509 (1948).

13. Jakob, M., and I. B. Fieldhouse, "Cooling by Forcing a Fluid Through a Porous Plate in Contact with a Hot Gas Stream, "Heat Transfer and Mechanics Institute, 1949.

14. Moore, N. P. W., and P. Grootenhuis, "Sweat Cooling," The Engineer, $189,230(1950)$.

15. Hatfield, M. R., "Fluid Flow Through Porous Carbon," Ind. Eng. Chem., 31,1419 (1939). 